\title{
Spectrophotometric Determination of Trace Amounts of Calcium Using the Calcium Complex with Alizarin
}

\author{
Hong-Wen Gao
}

\author{
School of Chemistry and Chemical Engineering, Anhui University, Hefei-230039, P. R. China
}

\begin{abstract}
A reação entre cálcio e alizarina (ALZ) foi investigada para determinação espectrofotométrica de cálcio em níveis de traços. O surfactante catiônico brometo de cetilmetilamônio (CMAB) foi usado com sucesso para aumentar a sensibilidade. $O$ método de correção beta foi empregado para determinar as propriedades do complexo Ca-ALZ, ao invés da espectrofotometria convencional. Os resultados revelaram que o complexo formado, $\mathrm{Ca}(\mathrm{ALZ})_{2}$, tem absortividade molar real igual a $3,74 \times 10^{3} \mathrm{~L} \mathrm{~mol}^{-1}$ $\mathrm{cm}^{-1} \mathrm{em} \lambda=630 \mathrm{~nm}$.
\end{abstract}

The reaction between calcium and alizarin (ALZ) was investigated for the spectrophotometric determination of trace amounts of calcium. The cationic surfactant, cetyltrimethylammonium bromide (CTAB) was useful to increase the sensitivity. The beta-correction method was applied for the determination of the properties of the Ca-ALZ complex instead of ordinary spectrophotometry. Results showed that the complex formed, expressed as $\mathrm{Ca}(\mathrm{ALZ})_{2}$, has a real molar absorptivity equal to $3.74 \times 10^{3} \mathrm{~L} \mathrm{~mol}^{-1} \mathrm{~cm}^{-1}$ at $630 \mathrm{~nm}$.

Keywords: beta-correction principle, calcium complex, alizarin, trace calcium

\section{Introduction}

Calcium exists extensively in nature. It is one of the elements necessary for the human body. Therefore, the absorption of calcium from food, drinking water, grain and so on is necessary to health. The chromogenic reagents, 3(2-chlorophenylazo)-6-(2- bromophenylazo)-4,5-dihydroxynaphthalene-2,7-disulfonic acid, ${ }^{1}$ ethanedial-bis (4-hydrobenzoylhydrazone), ${ }^{2}$ chloridazon $\mathrm{C},{ }^{3}$ rhodamine $\mathrm{B}^{4}$ and others have been used for the determination of calcium by spectrophotometry. Alizarin (ALZ) has been found to sensitively complex calcium at $\mathrm{pH} 5.2$; its structure is given below:<smiles>O=C(O)CN(CC(=O)O)Cc1cc2c(c(O)c1O)C(=O)c1ccccc1C2=O</smiles>

Derivatives of ALZ have already been applied for the determination of aluminum, ${ }^{5}$ of the hardness of water ${ }^{6}$ and heavy metal ions. ${ }^{7}$ Using this reaction, the determination of

e-mail:gaohw@mars.ahu.edu.cn the Ca-ALZ complex for trace amounts of calcium has been carried out by $\beta$-correction spectrophotometry. The presence of the cationic surfactant, cetyltrimethylammonium bromide (CTAB) may increase the analytical sensitivity because it can form a ternary complex together with $\mathrm{Ca}$ and ALZ. This report describes the determination of the properties of the Ca-ALZ complex, which includes the complex ratio and the real (not apparent) molar absorptivity of complex by the beta-correction spectrophotometric method ${ }^{8-10}$ instead of ordinary spectrophotometry. The beta-correction spectrophotometric method gives the absorption of the excess ALZ and the Ca-ALZ complex product so that a simpler operation and more acceptable results for the determination of the properties of the Ca-ALZ complex may be obtained than with conventional methods such as molar ratio, ${ }^{11}$ continuous variation, ${ }^{12}$ equilibrium movement, ${ }^{13}$ etc . Results show that the composition ratio of $\mathrm{Ca}$ to ALZ is $\mathrm{Ca}: \mathrm{ALZ}=1: 2$ and the real molar absorptivity of the complex is $3.74 \times 10^{3} \mathrm{~L} \mathrm{~mol}^{-1} \mathrm{~cm}^{-1}$ at $630 \mathrm{~nm}$. The presence of tartrate may mask the co-existing metal ions, except calcium and other alkaline earths. Beer's law was obeyed over the range 0-2.00 $\mathrm{mg} \mathrm{L}^{-1} \mathrm{Ca}(\mathrm{II})$ and the detection limit of calcium was $0.035 \mathrm{mg} \mathrm{L}^{-1}$. For analyzing samples, the recovery of calcium from standard solution was between 96.2 and $108 \%$ and the relative standard deviations less than $4.6 \%$. 


\section{Principle}

The following expression was earlier established ${ }^{5}$ for the determination of the real absorbance $\left(\boldsymbol{A}_{\boldsymbol{c}}\right)$ of a metal (M) complexed $\left(\mathbf{M} \mathbf{L}_{\gamma}\right)$ with a ligand $(\mathbf{L})$.

$A_{c}=\frac{\Delta A-\beta \Delta A^{\prime}}{1-\alpha \beta}$

The symbols $\Delta A$ and $\Delta A^{\prime}$ are the absorbances of the solutions of $\mathbf{M L}_{\gamma}$ and excess $\mathbf{L}$, which are measured at wavelengths $\lambda_{2}$ and $\lambda_{1}$ against a reagent blank, respectively. The correction constants, $\alpha$ and $\beta$ are obtained from the following equations by measuring $\mathbf{M L}_{\gamma}$ and $\mathbf{L}$ :

$\alpha=\frac{\varepsilon_{M L_{\gamma}}{ }^{\lambda 1}}{\varepsilon_{M L_{\gamma}}{ }^{\lambda 2}}$

and

$\beta=\frac{\varepsilon_{L}^{\lambda 2}}{\varepsilon_{L}^{\lambda 1}}$

The symbols $\boldsymbol{\varepsilon}_{\mathrm{ML} \gamma}{ }^{\lambda \mathbf{1}}, \boldsymbol{\varepsilon}_{\mathrm{ML} \gamma}{ }^{\lambda \mathbf{2}}, \boldsymbol{\varepsilon}_{\mathrm{L}}{ }^{\lambda \mathbf{1}}$ and $\boldsymbol{\varepsilon}_{\mathrm{L}}{ }^{\lambda \mathbf{2}}$ are the molar absorptivities of $\mathbf{M} \mathbf{L}_{\gamma}$ and $\mathbf{L}$ at wavelengths $\lambda_{1}$ and $\lambda_{2}$, respectively.

Because the apparent molar absorptivity $\left(\varepsilon_{\mathrm{a}}^{\lambda 2}\right)$ of complex $\mathbf{M L} \mathbf{L}_{\gamma}$ at wavelength $\lambda_{2}$ was calculated from the measured absorbance $(\Delta \mathbf{A})$, the real molar absorptivity $\left(\varepsilon_{\mathrm{r}}^{\lambda \mathbf{2}}\right)$ should be obtained from the real absorbance $\left(\mathbf{A}_{\mathbf{c}}\right)$ according to the following expression:

$\varepsilon_{r}^{\lambda 2}=\frac{A_{c}}{\delta C_{M}}$

The symbol $\delta$ indicates the thickness of cell and $C_{M}$ is the total concentration $\left(\mathrm{mol} \mathrm{L}^{-1}\right)$ of $\mathbf{M}$. The molar ratio $\left(\gamma^{\prime}\right)$ of $\mathbf{L}$ needed to complex $\mathbf{M}$ may be expressed as follows ${ }^{10}$ :

$\gamma^{\prime}=\eta \times \frac{C_{L}}{C_{M}}$

where

$\eta=\frac{\alpha \Delta A-\Delta A^{\prime}}{(1-\alpha \beta) A_{o}^{\prime}}$

The symbol $\eta$ indicates the effective fraction of $\mathbf{L}, C_{L}$ is the concentration $\left(\mathrm{mol} \mathrm{L}^{-1}\right)$ of $\mathbf{L}$ at the beginning and $A^{\prime}{ }_{0}$ is the absorbance of the blank reagent measured at wavelength $\lambda_{1} \cdot \gamma^{\prime}$ always approaches a maximum $\gamma$, which is a whole number named the stoichiometric ratio of the complex.

\section{Experimental}

\section{Absorption spectra}

Absorption spectra were recorded using a Model 7230 spectrophotometer (Shanghai Analytical Instrument Factory, China) with a 3 -cm cell.

A standard calcium (II) solution, $100.0 \mathrm{mg} \mathrm{L}^{-1} \mathrm{Ca}$ (II), was prepared by dissolving calcium carbonate (G. P., Shanghai Chemicals) in $0.01 \mathrm{~mol} \mathrm{~L}^{-1}$ hydrochloride acid. The ligand solution, $5.20 \mathrm{mmol} \mathrm{L}^{-1}$ ALZ, was prepared by dissolving $2.000 \mathrm{~g}$ of alizarin (Shanghai Reagents) in $100 \mathrm{~mL}$ of $2 \%$ cetyltrimethylammonium bromide (CTAB, Beijing Reagents) and diluting to $1000 \mathrm{~mL}$ with deionized water, where the surfactant, CTAB was helpful to increase the reaction sensitivity. The $\mathrm{pH} 5.2$ buffer solution was prepared with sodium acetate (A. R., Shanghai Chemicals) and acetic acid (A. R., Huainan Chemical Reagents, China) and it was used to adjust the acidity of the reaction solution. The masking reagent, $20 \%$ potassium sodium tartrate (A. R., Shanghai Reagents) was prepared for masking the other metals ions. All preparations used deionized water.

\section{Recommended procedures}

A known volume of a sample solution containing less than $50.0 \mu \mathrm{g}$ of calcium is taken in a $25-\mathrm{mL}$ volumetric flask. $2 \mathrm{~mL}$ of buffer solution is added, then $1 \mathrm{~mL}$ of masking reagent solution and $2.00 \mathrm{~mL}$ of ALZ solution. The mixture is diluted to $25 \mathrm{~mL}$ and mixed well. After $5 \mathrm{~min}$, the absorbances are measured at 470 and $630 \mathrm{~nm}$ against a reagent blank.

If the sample is solid, such as food or grain, it must be prepared as a solution. Firstly, $1.00 \mathrm{~g}$ of solid sample is turned into ash at $500{ }^{\circ} \mathrm{C}$ in a muffle furnace (Shandong, China). Then, the residue is dissolved in $20 \mathrm{~mL}$ of $6 \mathrm{~mol} \mathrm{~L}^{-1}$ hydrochloric acid and diluted to $100 \mathrm{~mL}$ with deionized water.

\section{Results and Discussion}

\section{Absorption spectra}

Figure 1 shows the absorption spectra of ALZ and the solution after reaction with $\mathrm{Ca}$. From curve $\mathrm{C}$, two wavelengths may be selected such that the difference in absorbance is maximized: 470 (valley) and $630 \mathrm{~nm}$ (peak). 
From curve $\mathrm{A}$, the $\beta$ value is calculated to be 0.556 and from curve $\mathrm{B}, \alpha$ is 0.10 . Because the $\alpha \beta$ value is much less than 1, the following expression is established: $\mathbf{A}_{\mathbf{c}} \approx \Delta \mathrm{A}$ $0.556 \Delta \mathrm{A}^{\prime}$.

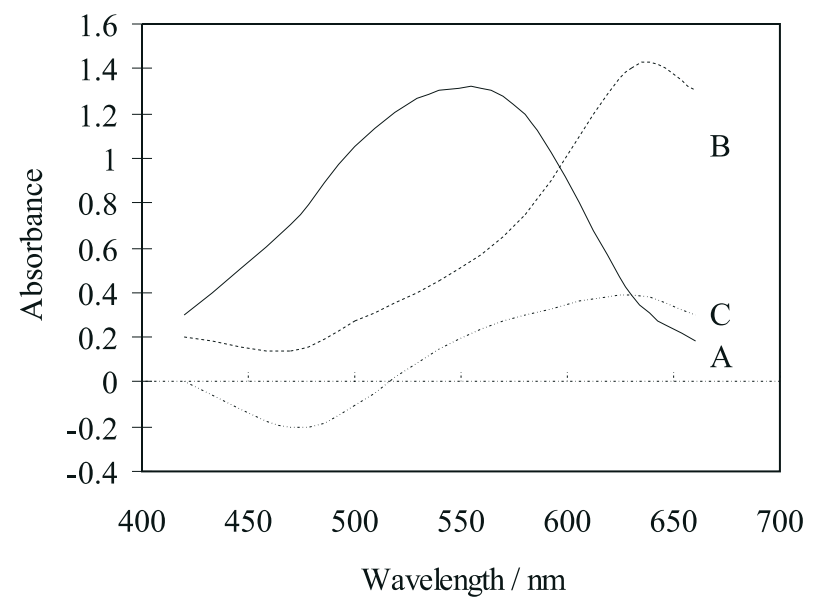

Figure 1. Absorption spectra of ALZ and calcium-ALZ at pH 5.2 in the presence of CTAB: A- $10.4 \mu \mathrm{mol}$ of ALZ, B- only Ca-ALZ complex, C- $\mathrm{Ca}(50.0 \mu \mathrm{g})-\mathrm{ALZ}(10.4 \mu \mathrm{mol})$ solution, A and B against water and $\mathrm{C}$ against reagent blank.

\section{Effect of ALZ concentration}

Figure 2 shows the effect of the concentration of the ALZ solution on the absorption of ALZ and its calcium reaction product. From curve B, the real absorption $\left(\mathbf{A}_{\mathbf{c}}\right)$ approaches a maximum when more than $0.50 \mathrm{~mL}$ of ALZ is added to the solution. In this study, $2.0 \mathrm{~mL}$ of ALZ solution was added. From curve B, we observe that the accurate composition ratio of $\mathrm{L}$ to $\mathrm{Ca}$ was obtained with

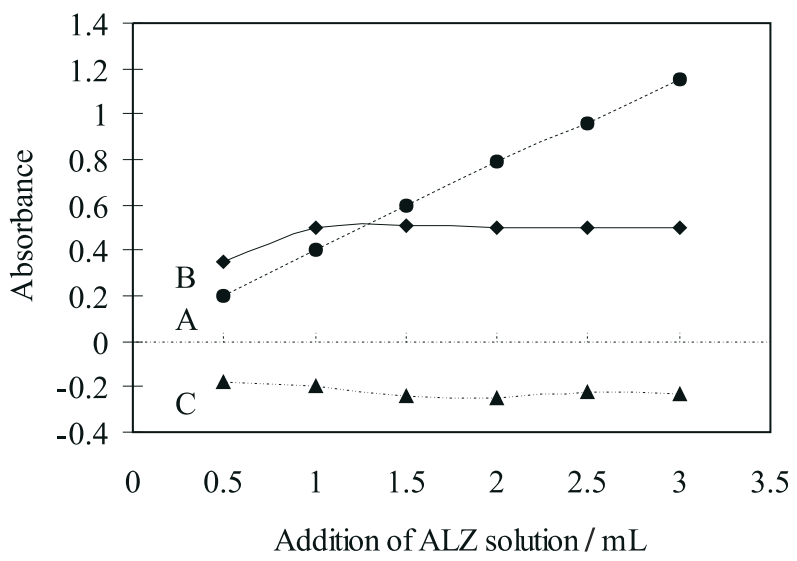

Figure 2. The effect of the addition of ALZ solution on the absorption of an ALZ solution and a $\mathrm{Ca}(50.0 \mu \mathrm{g})$ plus ALZ solution at $\mathrm{pH}$ 5.2: A- ALZ solution at $470 \mathrm{~nm}$ against water, B- real absorption of the $\mathrm{Ca}$ - ALZ complex at $630 \mathrm{~nm}, \mathrm{C}$ - measurable absorption of the CaALZ solution at $470 \mathrm{~nm}$ against reagent blank. difficulty by the molar ratio method because its inflexion point is unclear. However, from the $\gamma^{\prime}$ curve (Figure 3), we observe that $\gamma^{\prime}$ approaches the maximum and is constant at 2 when the addition of ALZ solution is more than 1.0 $\mathrm{mL}$. Therefore, the complex formed should be expressed as $\mathrm{Ca}(\mathrm{ALZ})_{2}$.

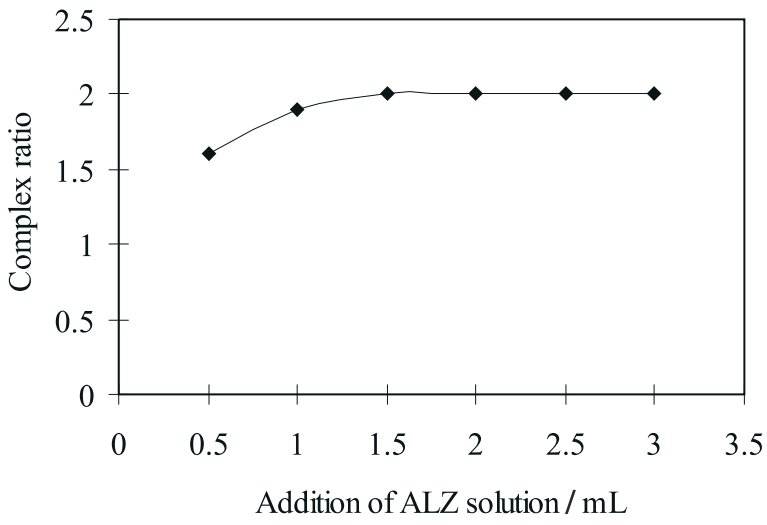

Figure 3. Effect of the addition of an ALZ solution on the composition ratio $\left(\gamma^{\prime}\right)$ of ALZ to Ca.

\section{Effect of other conditions}

The reaction between $\mathrm{Ca}(\mathrm{II})$ and $\mathrm{ALZ}$ can proceed rapidly at $\mathrm{pH} 4.5-6.5$. The absorption of a $\mathrm{Ca}(50.0 \mu \mathrm{g})$ ALZ solution approaches its maximum when the concentration of CTAB is between 0.01 and $0.1 \%$ in the reaction solution. The addition of $2.00 \mathrm{~mL}$ of the ALZCTAB solution may provide the necessary CTAB concentration to form the ternary complex with $\mathrm{Ca}$ (II) and ALZ. In addition, we observed that the reaction between calcium (II) and ALZ was complete in $2 \mathrm{~min}$ in the presence of CTAB. Measurement of the absorbances may therefore be carried out 5 min after the addition of an ALZ solution.

\section{Calibration graph}

A series of standard calcium solutions were prepared and the absorbance of each was measured and plotted. Two calibration curves, one of the real absorbance $\left(\mathbf{A}_{\mathbf{c}}\right)$ and the other of the measurable absorbance $(\Delta \mathbf{A})$ are shown in Figure 4. All of $\mathbf{A}_{\mathbf{c}}$ points seen in curve $\mathrm{A}$ fit a more linear curve than do $\Delta \mathbf{A}$ of curve $\mathrm{B}$. Therefore, the accuracy obtained by the recommended method is better than that obtained using single wavelength spectrophotometry. From the curves A and B, we can calculate the real molar absorptivity $\left(\varepsilon_{\mathrm{r}}\right)$ of the Ca-ALZ complex to be $3.74 \times 10^{3} \mathrm{~L}$ $\mathrm{mol}^{-1} \mathrm{~cm}^{-1}$ at $630 \mathrm{~nm}$ and its apparent value $\left(\varepsilon_{\mathrm{a}}\right)$ to be only $2.81 \times 10^{3} \mathrm{~L} \mathrm{~mol}^{-1} \mathrm{~cm}^{-1}$, respectively. It shows that the 


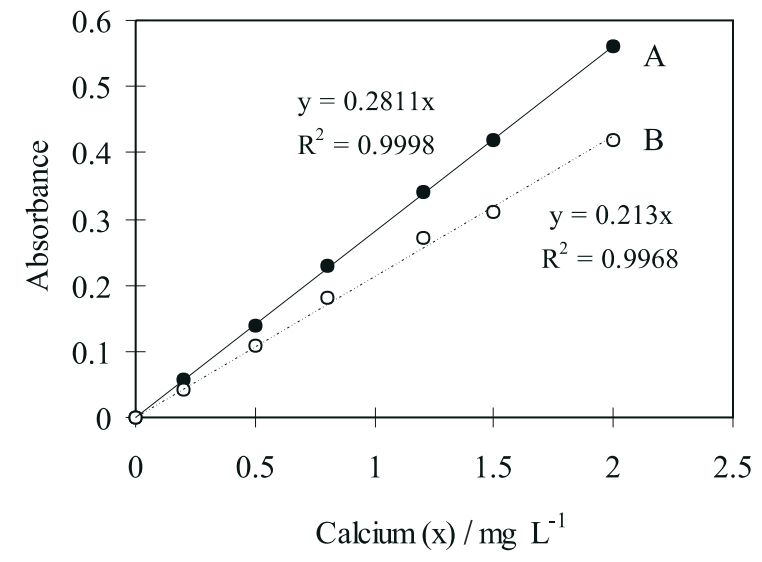

Figure 4. Standard curves for the determination of $\mathrm{Ca}$ at $630 \mathrm{~nm}$, using ALZ as reactant at $\mathrm{pH} 5.2$ in the presence of CTAB and sodium potassium tartrate: A- real absorption $\left(\mathrm{A}_{\mathrm{c}}\right)$; $\mathrm{B}$ - measurable absorption $(\Delta \mathrm{A})$.

sensitivity of the $\beta$-correction spectrophotometry was higher than that obtained by the single wavelength method.

\section{Precision and detection limit}

Ten replicate determinations of two standard solutions containing $2.50 \mu \mathrm{g}$ and $25.0 \mu \mathrm{g}$ of $\mathrm{Ca}$ (II) were carried out, respectively. Their relative standard deviations (RSDs) were 4.6 and $1.0 \%$. However, the RSDs for single wavelength spectrophotometry were 11.8 and $3.9 \%$, respectively. The precision for $\beta$-correction spectrophotometry was therefore better than that for the ordinary method.

At an $\mathbf{A}_{\mathbf{c}}$ of 0.010 , the detection limit of calcium is calculated at being only $0.035 \mu \mathrm{g} \mathrm{mL}^{-1}$ (about $0.9 \mu \mathrm{g}$ / $25 \mathrm{~mL})$.

\section{Effect of foreign ions}

The reagent sodium potassium tartrate was used as a masking agent for some metal ions except the alkaline earths. Once the recommended masking reagent was added to $2.00 \mathrm{mg} \mathrm{L}^{-1} \mathrm{Ca}$ (II), none of the following ions affect the direct determination: $100 \mathrm{mg} \mathrm{L}^{-1} \mathrm{Na}^{+}, \mathrm{K}^{+}, \mathrm{Cl}^{-}, \mathrm{SO}_{4}{ }^{2-}, \mathrm{F}^{-}$, $\mathrm{NO}_{3}^{-}, \mathrm{PO}_{4}^{3-} ; 10 \mathrm{mg} \mathrm{L}^{-1} \mathrm{Ti}^{4+}, \mathrm{Cr}^{3+}, \mathrm{Pb}^{2+}, \mathrm{Mn}^{2+}$ and $0.5 \mathrm{mg} \mathrm{L}^{-1}$ $\mathrm{Mg}^{2+}, \mathrm{Zn}^{2+}, \mathrm{Cu}^{2+}, \mathrm{Fe}^{2+}, \mathrm{Ni}^{2+}, \mathrm{Fe}^{3+}$. In general, the co-existing ions in food, water and grains do not affect the direct determination of trace amounts of calcium.
Analysis of samples

As a test of this method, calcium was determined in samples, for example special-use water, vegetables and food. The results determined are listed in Table 1. The average recovery of standard calcium was between 96.2 and $108 \%$ and the RSDs less than $4.6 \%$.

Table 1. Results determined for the calcium content of some samples

\begin{tabular}{lcccc}
\hline Sample & $\begin{array}{c}\text { Added } \\
\mathrm{mg} \mathrm{kg}^{-1}\end{array}$ & $\begin{array}{c}\text { Found* } \\
\mathrm{mg} \mathrm{kg}^{-1}\end{array}$ & $\begin{array}{c}\text { RSD } \\
\%\end{array}$ & $\begin{array}{c}\text { Mean recovery } \\
\%\end{array}$ \\
\hline Water & 0 & $\begin{array}{c}0.756 \\
1.237\end{array}$ & 3.4 & 96.2 \\
\hline Vegetable & 0 & 21.5 & 1.5 & 108 \\
& 20.0 & 43.1 & & 101 \\
\hline Foodstuffs & 0 & 3.56 & 4.6 & \\
& 5.00 & 8.60 & & \\
\hline
\end{tabular}

* average of six determinations

\section{Acknowledgments}

Financial supports from both the Natural Science Foundation of Anhui Province and the Natural Science Foundation of Anhui Education Council are gratefully acknowledged. I thank my colleagues Yu-Cheng LI and Shu-Ren SHI for the technical assistance.

\section{References}

1. Gao, H. W.; Zhang, P. F.; Zavod. Lab. 1998, 65, 4.

2. Wleteska, E.; Szczepaniak, Z.; Chem. Anal. (Warsaw) 1987, $32,461$.

3. Lau, Q. W.; Chan, S. F.; Mikrochim. Acta 1980, 1, 465.

4. Noluzktov, N. S.; Zh. Anal. Khim. 1970, 25, 1714.

5. Gao, H. W.; Shi, H. L.; Spectroscopy 1994, 9, 8-47.

6. Khalifa, M.; Chem. Anal. (Warsaw) 1996, 41, 357.

7. Xing, W.; Ingmane, F.; Talanta 1982, 29, 707.

8. Issa, Y. M.; Rizk, M. S.; Mohamed, H. A.; J. Ind. Chem. Soc. 1997, 74, 128.

9. Wrobel, K.; Kwievinska, B.; Godlewska, B.; Chem. Anal. (Warsaw) 1995, 40, 631.

10. Gao, H. W.; Zh. Anal. Khim. 1997, 52, 141.

11. Tikhonov, V. N.; Zh. Anal. Khim., 1975, 30, 1501.

12. Likussar, W.; Anal. Chem. 1973, 45, 1926.

13. Laearev, I.; Zavod. Lab. 1975, 41, 534.

Received: March 7, 2000

Published on the web: December 4, 2001 